\title{
Impoliteness in Power-imbalance and Power-neutral Relational Contexts: Evidence from a Persian TV Drama
}

\author{
Mohammad Hossein Keshavarz \\ Girne American University \\ North Cyprus \\ E-mail: keshavarz22@gmail.com \\ *Corresponding Author \\ Email : keshavarz22@gmail.com
}

DOI: https://doi.org/10.18326/jopr.v4i1.41-59

Copyright (C) The Author (s)

This work is licensed under a Creative Commons Attribution-ShareAlike 4.0 International License.

How to Cite: Keshavarz, M. (2022). Impoliteness in Power-imbalance and Power-neutral Relational Contexts: Evidence from a Persian TV Drama. Journal of Pragmatics Research, 4(1), 41-59. doi:https://doi.org/10.18326/jopr.v4i1.41-59

Submission
Track:
Received:
17-01-2022
Final Revision:
07-02--2022
Available online:
01-03-2022
Corresponding
Author:
keshavarz22@gmail.co
m

\section{ABSTRACT}

This study investigated impoliteness in relational contexts. Interlocutors analyzed the data from a Persian TV drama from two perspectives: intentionality and perception of impoliteness. Two relational contexts were identified: power-imbalance and power-neutral, each comprising two types of impoliteness: reciprocal and non-reciprocal. Reciprocal impoliteness occurred in hostile and conflictual situations where impoliteness was both intended by the speaker and perceived by the recipient as a direct face-attack. In non-reciprocal impoliteness, however, when power imbalance was due to family hierarchy, the recipient of impoliteness remained silent; in other situations, the intentional face-attack was tolerated, unless the recipient's social identity face was directly attacked. In power-neutral situations, impoliteness was not reciprocated when intimacy existed between the interactants. It was neither intended nor perceived as face threatening; however, direct face-attack was reciprocal in hostile situations. The findings of the present study point to the significant role of the relational context in the interpretation of impoliteness.

Keywords: Impoliteness; reciprocal; non-reciprocal; relational contexts; power-imbalance; power-neutral 


\section{INTRODUCTION}

Films and TV dramas provide rich socio-cultural and linguistic data for research studies in these fields since they "deal with thoughts and practical experiences of everyday life" (Lambertz \& Hebrok, 2011, p. 40). As Rose (2001) asserts, the film is "an essentially unexplored potential resource for research on discourse and pragmatics" (p.309). The results of her study indicate that "film language appears to be most representative of naturally-occurring speech from a pragmalinguistic perspective" (Rose, 2001, p. 309). Research also suggests that TV series, to a large extent, reflect real-life situations and cultural changes in the lifestyle of people (Ahmad, 2012; Brunsdon, 2000). Since TV dramas attract a large audience, they are bound to impact society (Gannon, 2009).

TV dramas have been investigated from different perspectives. Cevik (2014), for example, studied Turkish TV dramas from a sociocultural perspective and claimed that they function "as a cultural diplomacy tool" (p. 78), introducing Turkish culture to the outside world, in particular to neighboring countries in the Middle East. This perspective relates to sociopragmatic and speech act studies, including impoliteness, using TV drama data (e.g., Culpeper, 2005; Dzo'ul \& Pramono, 2021; Izzani, 2020; Keshavarz, Cetereisi, \& Asit, 2020; Khazdouzian, 2018; Haryanti, 2016). Some researchers have also examined TV dramas from the point of view of feminism and the role of women in society (e.g., Ahmad, 2012; Gannon, 2009; Hohenstein \& Thalmann, 2019; Lambertz \& Hebro, 2011). However, to the best of the present author's knowledge, impoliteness in Persian TV dramas has not been investigated yet. Therefore, to fill this research gap, the present study seeks to analyze the use of impoliteness in a popular Persian TV drama.

Now let us turn to impoliteness, which is the main focus of the present study. Considering the complexity of impoliteness and the variables involved in its use and interpretation, defining it is not straightforward. Therefore, different scholars have defined impoliteness from different perspectives. As Bousfield (2008) notes, "definitions of impoliteness vary amongst researchers working on the phenomenon. They vary even amongst those who have worked together in the past" (p. 30). Culpeper, Bousfield and Wichmann (2003) define impoliteness as "the use of strategies designed to attack face, and thereby cause social conflict and disharmony" (p.1545), while Bousfield (2008) defines it as "constituting the issuing of intentionally gratuitous and conflictive face-threatening acts (FTAs) that are purposefully performed" (p.132). To Culpeper (2005), "impoliteness comes about when: (1) the speaker communicates face-attack intentionally, or (2) the hearer perceives or constructs behavior as intentionally face-attacking, or a combination of (1) and (2)" (p.38). Culpeper (2005) further elaborates on attacks on the face and discusses two types of face: quality face and social identity face. He defines these two types of faces as "quality face (e.g., attacks on the inadequacy of the contestant in answering the questions) and Social Identity face (e.g., attacks on the contestant's regional accent and job)" (p.40). Similarly, Limberg (2009) views impoliteness as "an intentional form of face-aggravation caused by verbal and 
nonverbal means and interactively construed in a particular context" (p.1376). As can be observed, all of these definitions emphasize intentionality and face-threatening features of impoliteness. However, discursive/relational approaches to impoliteness are not primarily concerned with intentionality; rather, they "focus on the way that discourses inform what speakers think is possible to say, how they view their relations with others and with their communities, and how power impacts on these relations" (Van Der Bom \& Mills, 2015, p. 180). In other words, (im)politeness depends on how participants in different contexts and cultures perceive it. For example, suppose in a culture like Arabic (Ghazzoul, 2019), directness is the norm of interaction. In that case, it is not perceived as being impolite by interlocutors, while the same speech act is considered impolite in some other cultures and languages like English. Even within a single society and culture, the same linguistic form may or may not be perceived as impolite depending on the relationship between interlocutors. A case in point is the Persian expression khafe sho 'shut up" in the context of Iran, as will be illustrated in the discussion of the data. Therefore, "it is not self-evident that a particular linguistic utterance is unanimously perceived as (im)polite by everyone involved in the interaction" (Locher, 2006, p. 252). Locher and Watts (2005) have made an interesting analogy by saying "just as beauty is in the eye of the beholder, politeness depends on the individual's perception as well" (p. 29). Locher (2006) further argues that "The discursive approach to politeness recognizes the evaluative and norm-oriented character of politeness by claiming that politeness belongs to the interpersonal level of linguistic interaction" (p.253). The present study aims to encompass both of these features, i.e., intentionality and discursive elements of impoliteness, as will be discussed in the results section.

Concerning impoliteness strategies, Culpepper (1996 and 2005) divided them into five categories: bald on record impoliteness, positive impoliteness, negative impoliteness, sarcasm or mock politeness, and withholding politeness. He used the super label strategies instead of politeness strategies; however, the term 'strategy' is used for consistency here. These strategies are summarized below.

In bald on record impoliteness, the face-threatening act is performed in an explicit, clear, unambiguous, and concise manner in circumstances where the face of the addressee is attacked. Positive impoliteness refers to the use of strategies intended to damage the addressee's positive face-wants, such as ignoring a person's self-image, excluding them from a group, and making them uncomfortable by using inappropriate identity markers (e.g., using professional titles instead of intimate ones, like 'mate'). On the other hand, negative impoliteness refers to strategies designed to damage the addressee's negative face wants, i.e., imposing on them or ridiculing and scorning them, thereby causing them embarrassment and humiliation. Culpeper defines sarcasm or mock politeness as strategies in which the face-threatening act is performed indirectly using politeness strategies that are insincere and contradictory. For example, saying something ironically means just the opposite of what is said, such as 'your office is tidy,' while it is 
untidy. Finally, withholding politeness refers to a lack of politeness where the listener would expect it. For instance, when the speaker does not apologize for wrongdoing or acknowledge the interlocutor's appreciation.

Now let us turn to the definition of response to impoliteness, which has not received due attention in the literature. As Culpeper, Bousfield, and Bichmann (2003) note, "research on both politeness and impoliteness has tended to overlook what the recipient of face threat or attack does" (p.1562). Of the few studies conducted on response strategies to impoliteness, Culpeper, Boufield, and Wichmann (2003) are perhaps the most comprehensive. Drawing on Culpeper (1996), Harris, Gergen, and Lannaman (1986), Culpeper et al. (2003) state that the recipient of an impoliteness face attack has two main options available to them: either to respond or to remain silent and do not counter face attack.

In other words, the recipient of the face attack may accept the legitimacy of the impoliteness act by the speaker, i.e., they may accept the blame for provoking the act of impoliteness by having done something wrong. In this case, the recipient may or may not apologize. However, if the recipient decides to counter the face-threatening impoliteness, there are two options available to them: they may be offensive or defensive in their responses to impoliteness. As the name implies, the offensive response involves countering a face attack aggressively with a face attack; whereas "defensive strategies primarily counter face attack by defending one's own face"... "such strategies seek to deflect, block or otherwise manage the face attack" (Culpeper et al. 2003, p. 1562). The contribution of the present study to the literature is that it uses data from a Persian TV drama to shed light on the use of impoliteness in two main relational contexts, i.e., powerimbalance and power-neutral, each comprising two types of impoliteness: reciprocal and nonreciprocal. The study will also present data on the two main types of face-attack response strategies, namely defensive and offensive strategies.

\section{RESEARCH METHOD}

The present study's design is descriptive qualitative since the discussion of the results is presented descriptively. The data for this study come from a popular Persian TV drama called Asheghaneh' Romantic'. It was written, produced, and directed by Manoochehr Hadi and was premiered and aired in 2017. Asheghaneh portrays modern changes in Iranian society, particularly the social life and relationship of young people. It is a narrative of a few friends and families and their problems. The story begins with an advertising company run by three close friends: Reza, Soheil, and Peyman. In addition to humor and romantic scenes, there are many arguments, quarrels, and fights in this TV drama that trigger impoliteness. Therefore, it was considered a good candidate for the present study.

Like other TV dramas, Asheghaneh consists of a series of televisual stories in different episodes consisting of the succession of events, usually with the involvement of more than 
two characters in each scene. Initially, the researcher for entertainment during his leisure time watched Asheghaneh. However, being interested in socio-pragmatics, the frequent use of different impoliteness in the soap gave him the impetus to carry out a qualitative descriptive analysis of the data.

To find sufficient number of impoliteness cases in the TV series, all the 17 episodes were watched by the researcher; however, since the focus of the study was impoliteness, only the dialogs containing impolite utterances were considered for further analysis. Each episode lasted about 50 minutes and was broadcast every Wednesday night. The objective was to identify different types and strategies of impoliteness and responses to face-attacks in the drama's dyadic and/or multiparty interactions, i.e., interactions between two or more characters in a scene, as illustrated in the excerpts below. Accordingly, 11 out of 17 episodes, which provided rich data on impoliteness, were chosen for data analysis. Scenes containing instances of impoliteness were written down, and the interactions were transcribed for data analysis. The researcher based on his native language intuition and linguistic background did the transcription. To present the transcribed text more readable, the use of technical phonetic symbols was minimized, and instead, more use was made of familiar orthographic digraphs (e.g., 'sh' instead of $/ \int /$, 'kh' for /x/, etc.). The transcription of original Persian utterances and their idiomatic English translations are provided in the Results \& Discussion section below.

\section{RESULTS \& DISCUSSION}

The bottom-up analysis of the data yielded two types of relational contexts in which impoliteness occurred: power-imbalance versus power-neutral. In each of these two situations, two types of impoliteness strategies emerged: reciprocal versus non-reciprocal. These are illustrated in Figure 1.

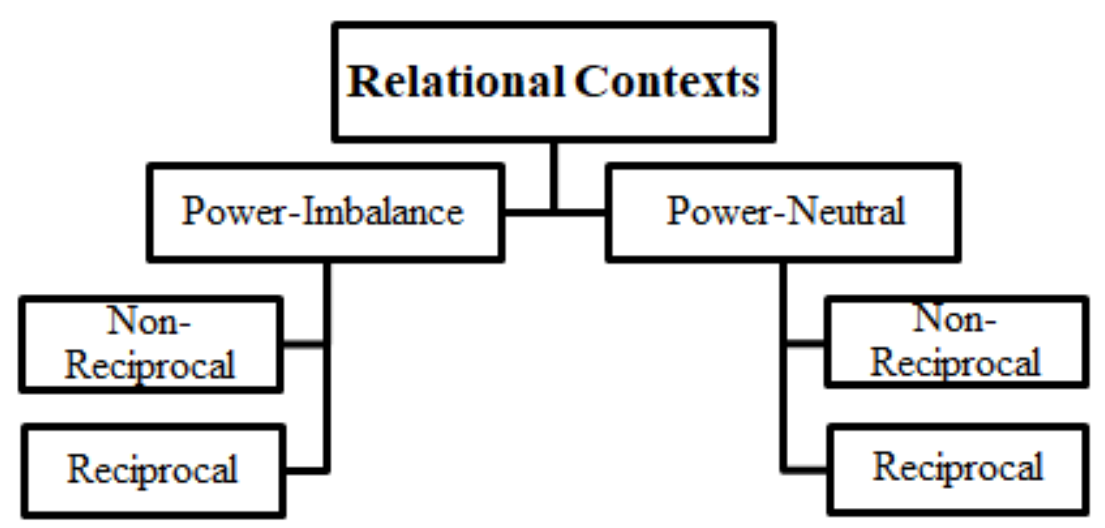

Figure 1. Relational contexts and types of impoliteness

The following Excerpts illustrate these different types of impoliteness and relational contexts. 


\section{Non-reciprocal impoliteness in power-imbalance relational contexts}

Excerpt 1. Background: Pegah (P), a young gynecologist from an affluent family, routinely scolds and insults her husband, Soheil (S), because she has high status (being a doctor) and wealth (possessing a luxurious apartment in an affluent region of Tehran, and an expensive villa in the Caspian Sea region), while Soheil does not have any of these privileges. Therefore, his wife has power over him. Soheil once opened up to his close friend, Reza, about his relationship with his wife and said:

S: un ra?is-e, dastur mide, man ham migaem chashm. man shodaem parcestar yek saeg.

She is the boss, she issues orders and I obey. I have become her dog's nurse.

Note 1. chashm 'eye' or ruye chashmam 'on my eye' is a typical Persian expression when one willingly does somebody a favor, or obeys the orders of a superior.

Note 2. The above sentence is a case of reported speech, and not an utterance containing impoliteness.

With this background, now consider how Pegah insults her husband in the following exchanges.

Scenario: Pegah is sitting on the sofa relaxing and watching Dr. Oz's satellite program when Soheil comes home and opens the door seeing that Pegah's dog, Poppet, has made everywhere dirty by leaving mess (excrement) on the floor, but he does not dare to complain directly and openly about it. He says hello, but his wife just ignores him and continues eating her snack without bothering to greet him back. Then, Soheil goes to the kitchen to wash his hands and Pegah gets angry, and the following conversation occurs between them.

P: ashpazkhane jaye dast shostcen nist aqa, hezar daefe bet goftcm

I've told you a thousand time that kitchen is not the right place to wash your hands, Sir.

In this utterance, Pegah uses the title 'Sir' in a derogatory fashion; she is contemptuous and scolds Soheil.

S: vali khune jaye sag negah dashtoene

But a house is the right place to keep dogs.

In this move, Soheil indirectly and sarcastically complains about the dog as he does not dare to criticize his wife openly.

$\mathrm{P}$ : in che taerze harf zadane

How dare you talk to me like this (uttered aggressively and from the position of power indicating that

$\mathrm{S}$ has no right to criticize her, even indirectly).

S: chetori harf mizanom. ye negah dorovaret bendaz. sage khune ra be gand keshide

(Gently and politely)What did I say. Take a look around you. The dog has made a mess out of everywhere.

P: bet goftam papet adaet nadare tanha tu khune bemune. khub qarar bud bebarish mahd, 


\section{chera naebordish?}

I have told you before that Puppet is not used to staying at home alone. Well, you were supposed to take him to the nursery, why didn't you? (complainingly)

\section{S: neresidam, kar dashtom Pegah jan, jalase dashtæm azize maen}

I couldn't, I was busy dear Pegah, I had a meeting my dear (talking politely and apologetically using endearment terms).

As can be seen, in his defensive response strategy, Soheil tries to manage and deflect impoliteness and attack to his face.

\section{P: bejaye in harfha ye jaru biar injaha ra tamiz kon, ba?d ham ye tei bekesh}

Instead of saying these, bring a broom and clean here, then mop the floor.

(Being annoyed by these orders, S goes to the bathroom and shuts the door)

\section{P: soheil shenidi chi goftam}

Soheil, did you hear what I said? (angrily, shouting and with contempt implying why didn't you follow my order).

Then, Soheil comes to the scene with a broom and dustpan and begins to clean the dog's stool (while still wearing his tie as he did not get a chance to change his clothes).

As observed, this conversation is full of contempt, belittling, and intentional impoliteness on the part of Soheil's wife since she has power over her husband. The exchanges show how defensive Soheil is in trying to deflect and manage the attack to his face. He mildly criticizes his wife for keeping a dog at home, but his wife aggressively and from the position of power says: "How dare you talk to me like this". Being defensive, Soheil says softly and politely: "What did I say. Take a look around you...”. Despite this, Pegah orders him to bring a broom and clean the mess, then mop the floor. But when $\mathrm{S}$ goes to the bathroom and shuts the door, being annoyed by these orders, Pegah shouts at him and tells him to do what she ordered him to do. Soheil, being in a weak position, tries to tolerate and manage his wife's continuous face attacks to avoid confrontation.

Excerpt 2. In the TV drama Asheghaneh, Haj Yunes (a wealthy and religious businessman) frequently attacks the quality and social identity face of his younger son, Reza, even in front of his wife. In one scene, Haj Yunes encourages Reza to close his advertising company and work for him in his enterprise, instead. After Reza politely rejects the offer, Haj Yunes gets upset and says: lajbazio kale shaq, bara hamine ke darja mizani

You are obstinate and bull-headed, that's why you do not get anywhere.

Reza who is a grown up man and the father of a child was obviously offended by these remarks, but instead of saying anything that may disrespect his father he looks down and remains silent as a sign of respect. However, his father continues scolding and belittling him indirectly by comparing him with his elder brother, as follows: 
dadash mohsento bebin, bahushe ke tuneste khodesho be injaha beresune. motmaenam ba jorboze'i ke dare tu entekhabat rai miare

Look at your brother Mohsen. He is smart, that's why he has been able to climb the ladder (implying that you are not intelligent). Certainly, with the potentials that he has he will win the election [for the parliament]

Needless to say, his father's humiliating and belittling remarks are perceived by Reza to be impolite; however, owing to power imbalance due to family hierarchy in Iranian culture, he does not reciprocate face-attacks.

\section{Reciprocal Impoliteness in power-imbalance relations}

Excerpt 3. Soheil has taken Poppet, Pegah's dog, out but he loses her. When he comes home empty handed, his wife gets extremely angry and starts attacking him verbally since Poppet is her prize possession.

P: hamin alan miri, gom mishi aez in vila miri birun

You get lost and leave this villa right away.

S: Pegah (just calling her name with rising intonation, pleading her to stop attacking his face).

However, Pegah ignores his pleading and becomes more aggressive. She holds Soheil by the arm and forces him out of the villa while saying:

P: age peidash nakkerdi baernemigardi. boro gomsho byaresh.

If you don't find her, you won't come back here. Get lost and bring her back.

S: nakon.

Stop it (stop harassing me)

At this moment Soheil asks his guests, Reza and his wife, to go upstairs as he doesn't want them to witness such an unpleasant and aggressive confrontation.

P: chekar be una dari. bezar hame befahmand cheqadr bi orze'i

Why do you ask them to go upstairs? Let everybody know how incompetent you are.

S: jelo mardom sedato biyar pa'in. mon darket mikonam, asheqesh budi, mifahmom,vabaste budi besh. $\quad$ mage man amdi kardam in kar ro? ye juri harf mizani engar man bordam sar be nistesh kardam. adam vase ye sag injuri ba shoharesh harf nemizane

Don't raise your voice in front of other people. I understand you, you loved her, I understand you were attached to her emotionally. I haven't lost her intentionally, have I? You talk as if I have taken her to get rid of her. One wouldn't talk to her husband like this just for a dog.

As can be seen, in these exchanges, Soheil tolerates his wife's impolite behavior and tries to deflect direct confrontation, but she continues attacking his face in front of their guests.

P: bekhatere je sag nist. to fekr mikoni bekhatere ye sage, sag nist u. to bi arzeshi, budo nabude $u$ kheili arzeshes az to bishtare. to tu zendegi mon hich farqi nemikoni, vali budo nabude ut $u$ zendegi moen mikone. 
It's not just for a dog. You think it's a dog-she is not a dog. She is more valuable than you. You are worthless-your existence doesn't make any difference to me, but hers does.

At this point, Soheil, whose social face has been severely damaged and has been badly humiliated in front of his friends, becomes infuriated and starts attacking her back verbally, as follows:

\section{S: bebænd un dahaeneto}

Shut your [big] mouth.

P: to dahaneto beband

You shut your mouth.

S: daefe akharete ke jelo mardam intori ba man harf mizani ha mizanam tu dahanet sedaye papet ra daerbiari

It's the last time you talk to me like this in front of others, ha (interjection)! I'll hit you in the mouth so that you'll howl like your dog.

$\mathrm{P}$ : to qalat kardi.

You dare to.

S: ahmaq.

Idiot!

P: to qaelaet mikoni. hich qaelati nemituni bekoni

You dare to. You can't do a damn thing.

S: cehmoeq

Idiot!

P: achmaeq to?i, badbakht to harche dari sadaqe sare manu khancevadam dari

You are idiot, you miserable thing, whatever you have is because of me and my family.

S: chekar kardin baray maen

What have you done for me?

Then, Pegah insults his father and family, which is the red line for Soheil, so he becomes inflamed, picks an expensive vase from the table and throws it on the floor to break, walks in the kitchen like crazy, and uses rather offensive language calling her names while yelling at her.

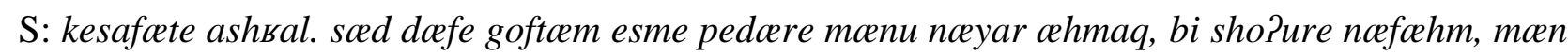
asheqe to budam ke bahat ezdevaj kardam, zabun nafahm.

You filthy jerk. I have told you a hundred times not to mention my father's name idiot. Fathead, moron, I was in love with you that's why I married you (not for your wealth), you idiot.

As the above exchanges illustrate, Pegah repeatedly uses bald-on-record face-attacks. Soheil, on the other hand, is first defensive and does not want to reciprocate impoliteness due to power imbalance. Instead, he tries to calm her down and deflect confrontation, but when she starts attacking his social identity face in front of his friends, he becomes furious and reciprocate impoliteness regardless of his weaker position. 


\section{Non-reciprocal Impoliteness in a power-neutral relations}

The following Excerpts exemplify cases of non-reciprocal impoliteness in a power-neutral relations.

Excerpt 4. Three close friends and partners, Reza, Soheil and Peyman, are having a serious talk in their advertising company. However, Peyman is not a serious person and always uses his sense of humor. In the following utterance, Reza, who is upset with Peyman as he keeps talking and getting on Reza's nerves, utters the following impolite sentence:

R: khafe khun migiri ya mikhai ta shab hamintor mozakhraef begi.

Will you shut up or you want to talk nonsense until evening?

The Persian expression khafe khun gereftaen 'shut up' is potentially offensive and impolite, which may provoke confrontation. However, given the intimate relationship between the interlocutors, Peyman does not perceive this utterance as impolite. Similarly, the intention of the speaker (Reza) is not to genuinely attack the face of his friend.

Excerpt 5. Mahmud is angry about the people (a singer and his crew) his finacée has invited to his villa since they have made a mess of the place before they arrived there. He wants them to leave, but Hedye (his finacée) tries to change his mind by using affectionate language:

$\mathrm{H}:$ eshqaem, bemunaen (while looking at him pleasingly)

My love, let them stay please.

M: ey morde shur un cheshmato bebare (while he accepts)

I approve because of your beautiful eyes.

$\mathrm{H}$ : She smiles and is pleased to hear this, instead of getting upset.

In Persian, expressions like morde shur heikal/cheshmato bebare, which means 'damn you', are offensive and are heard in quarrels and arguments. However, in the above exchange it is taken as a compliment by the hearer (Hedye) given their romantic relationship.

(Note: In Islamic countries, when someone dies his/her body will be washed, as part of a religious ceremony. This is similar to baptism in Christianity)

Excerpt 6. In this scene, Peyman, while answering a telephone call from his girlfriend uses an offensive term, as follows:

alo eshqe maen, tule sag, halet chetore?

Hello my love, how are you puppy?

Traditionally, it is extremely impolite and offensive to call or refer to someone as a dog on religious and cultural grounds. This metaphor is normally used in confrontations and fights as it provokes hostile reactions. However, in this case the intention of the speaker is not to insult his girlfriend, rather to utilize the animal metaphor to show his affection. Similarly, his girlfriend is unlikely to be offended by being called a puppy given that keeping puppies at home and showing 
affection towards them has become popular amongst the affluent and younger generation of Iranians, a practice that is still not approved of by the older generation, in particular religious people.

Excerpt 7. In this Excerpt, Soheil is complaining about his close friend's being bad-tempered, as follows:

che margete Reza, az sobh shodi borje zahre mar, az hame chi bahane migiri.

What the hell is wrong with you Reza, since this morning you've become so badtempered, you nag about everything.

Reza's reaction: He does not take offence and remains silent thinking about the project they are discussing.

In Iranian culture, words and expressions associated with death are considered taboo and are avoided unless people are angry with one another. The Persian expression che mærgete, like other expressions such as boro bemir 'go and die/go to Hell', is impolite and is avoided under normal circumstances; however, owing to history of friendship between the interlocutors it is not intended nor is it perceived as impoliteness. Of course, the English translation of this expression (What's wrong with you?) sounds quite normal and is not considered impolite; however, when we consider such expressions in the context of Iran we will find that they are indeed offensive and in cases of genuine impoliteness they provoke quarrels and fights.

Similarly, borje zahre mar 'the tower of venom' is a negative comment given to illtempered people. Though not as offensive as the first expression, under normal circumstances the hearer will not appreciate such a comment and will get upset.

Excerpt 8. In a scene of the TV drama, Peyman tells his guest, Soheil, to leave and go to his house:

pasho boro khunatun

Get up and go home.

In Iranian culture, it is extremely impolite to tell a guest to leave and go to their house. However, considering the intimate relationship between the speaker and the address, Soheil does not get upset and just ignores what Peyman has said and remains seated.

\section{Reciprocal impoliteness in power-neutral relations}

Excerpt 9. In a scene of the soap opera, Reza has a confrontation with Gisu, whom he thinks has a clandestine relationship with his affluent and so-called pious father, as the following exchanges illustrate.

$\mathrm{R}$ : bebakhshid khanom. mishe chand lahze vaqtetun ra begiram

Excuse me, Ma'am. May I take some of your time?

G: nakheir 
Nope!

As can be seen, in the first exchange, Reza approaches Gisu in a courteous manner, but the latter withholds politeness. This is perhaps rooted in family education in Iran since girls are advised not be friendly with strangers. However, $\mathrm{R}$ is persistent and in the next move she assures her that his purpose is not to do her any harm in order to attract her cooperation:

$\mathrm{R}$ : man mozahem nistam, kari ham be karetun næedaram. faeqat mikhoestam bahatun harf bezonoem

I don't want to bother you, and I don't want to interfere with your affairs. I just wanted to talk to you.

G: che harfi, mon ba foma harfi noedaram

What about? I don't have anything to talk about with you.

Then, she opens the car door again trying to get in, but Reza prevents her and says:

R: miduni moen kiaem. man pesare haj yunesam, hamunke bakhtcek shodi tu zendegish, homunke barash khab didi

Do you know who I am? I'm Haj Yunes's son, whom you've attached yourself to, whom you have plans for.

G: haj yunes kie? boro peje karet

Who is Haj Yunes? Get away!

$\mathrm{R}$ : chaend ruze eine saye donbaletam. midunam bash qaerar mizari, tu sherkæt, resturan, tu park. dige bash koja miri? karet ine, na?

I've been following you just like a shadow during the last few days. I know where you

Meet with him, in his office, restaurant, in parks. Where else do you go with him? That is your job, isn't it? (implying she is a prostitute)

Listening to Reza's accusation, Gisu gets furious and slaps him in the face, and says: G: khafe sho

Shut up!

After this face-attack, she opens the door and gets in the car, but Reza goes to the other side quickly and opens the door, and says:

$\mathrm{R}$ : boro qolabeto jaye dige bendaz, aevazi u nave dare

Go and try your chance somewhere else you jerk, he has got grandchildren (and then he leaves angrily).

As can be seen, in this Excerpt there is a gradual transition from politeness to direct impoliteness due to confrontation and mood change. First, Reza approaches Gisu in a polite manner and asks if he can talk to her. He uses the courtesy expression bebakhshid khanom 'excuse me Madam', and then asks her permission to talk to her for a few seconds. However, since women normally do not trust strange men, particularly when they invade their private zone (as Reza gets 
very close to her when she wants to get in her car), Gisu says she does not want to talk to him. However, since Reza does not want to give up they start attacking each other's face deliberately to the extent that Gisu slaps him in the face when he accuses her of having relations with his father. As can be seen, cases of impoliteness are intended by the speaker to be face-threatening and perceived by the interlocutor so.

\section{Excerpt 10.}

After Mahmood accuses Reza of helping his wife to take his assets and run away, Reza gets furious and shouts while pushing Mahmood away: chera chertopert migi marde hesabi, boro har qaelati doost dari bekon

Why are you talking nonsense, you idiot? Get lost and do whatever damn thing you want to do.

At this bald on record face-attack, the bodyguards attack Reza and beat him up. Then, Reza shouts and tells Mahmood angrily to take his contract and get lost:

...mituni [qarardad ra] bardari beri gureto gom koni-celbate baed aez taesfie hesab

You can take it [the contract] and get lost, of course after paying the rest of your due.

Then, the tall bodyguard insults Reza, and Reza says:

boro gom sho baba

Get lost you.

Note that the Persian word baba 'father' is used in a derogatory sense here. Together boro gom sho baba means 'get lost or go fly kite', which is intended and perceived as a case of baldon-record impoliteness used only in provocative confrontation.

After further confrontation and being beaten by Mahmood's bodyguards, Reza says angrily:

age aelan guretun ra gom kardin ke hich, vagarna khodam zang mizanam be polis

You get lost right away or else I'll call the police myself.

As can be seen, in this quarrel scene, Mahmood, who wrongly assumes that Reza and his friends have to do with his wife's swindling him out of his money and possessions, enters the scene aggressively and furiously to the extent that not only he and his men attack Reza's verbally, but also his bodyguards beat Reza up. Impoliteness in such cases is to be anticipated as the situation and mood of the speakers call for it and the recipient of impoliteness, in this case Reza, responds with offense and aggression. Needless to say, Mahmood's intention in calling on Reza's company is to deliberately insult and attack his face for the reasons explained above, hence the intentionality aspect of this speech act. Discursively-speaking, Mahmood's face-threatening intention is clearly and easily perceived by his interlocutor, Reza, who is provoked to engage in this face-threatening act and counters face-attack with offense and aggression.

Excerpt 11. Having lost the car race to a young lady named Hedye $(\mathrm{H})$, being in a fighting mood, Peyman $(\mathrm{P})$ gets off his car and approaches $\mathrm{H}$ and her race partner and tells them:

(Note that in Iranian culture, it is against the dignity of a man to be defeated by a woman). 
P: yebar dige inja bebinameton ...

If I see you here once more. (threatening them, while being interrupted by H's friend)

H's friend: oh kheili dari zer zer mikoni ha

Oh, you're talking a lot of nonsense ha.

\section{P: beband un gale ra}

Shut your big mouth.

H's F: boro baba

Go fly kite/Get lost!

The Persian expression zer zer kardan has a much more negative load than 'talking nonsense' in English as it is considered very rude and is used in confrontations and clashes, especially among the youth.

Similarly, the expression beband un gale ra 'Shut your big mouth' is extremely rude. In this expression, 'a big mouth' is derogatorily compared to a 'shoe cover', which is normally big and loose (compared to shoes). This metaphor is used in skirmishes as it usually provokes a fight.

Also the expression boro baba 'get lost or go fly kite' is another rude expression and if it is used in arguments it is considered provocative.

As mentioned before, the bottom-up analysis of the data yielded two distinct relational contexts: power-imbalance and power-neutral. Two main types of impoliteness emerged from each of these two contexts: non-reciprocal and reciprocal. The analysis of the data shows that power relationship is a key factor affecting both politeness and impoliteness, as also asserted by Mills (2009), and Watts (2003). As the above excerpts show, in an asymmetrical relationship, the superior normally takes advantage of his/her status, and exercises power to attack the face of those in a weaker position. This finding supports the results of other studies such as Bousfield and Locher (2008), Culpeper (1996), and Khatib and Lotfi (2015). Khatip and Lotfi (2015) found "a positive direct relationship between impoliteness and power in the Persian questionnaire suggesting that when the speaker has more power over the interlocutor, he/she uses more impoliteness strategies and when the speaker has less power, he/she uses less impoliteness strategies" (p. 55). In the same vein, Culpeper (1996) claims that "a powerful participant has more freedom to be impolite, because he or she can (a) reduce the ability of the less powerful participant to retaliate with impoliteness (e.g. through the denial of speaking rights), and (b) threaten more severe retaliation should the less powerful participant be impolite" (p. 354).

Analysis of Excerpt 1 above reveals that the character, Soheil, did not reciprocate impoliteness, and instead tried to deflect his wife's offensive behavior due to power imbalance. As explained in the Results Section, his wife, Pegah, had power over him as she was affluent and enjoyed high status as a physician, while Soheil did not have any of those privileges. This finding is in line with those of studies based on Western dramas (e.g., Bousfield, 2008; Culpeper, 1996; 
Laitenen, 2011). For example, Bousfield (2008) reports that a restaurant owner and head chef in a TV drama, Gordon Ramsay, frequently berated members of his staff, but they often chose not to respond to his face-attacks due to their weaker power position.

Another example of non-reciprocal impoliteness in power-imbalance relations is in the case of family hierarchy in Iranian culture. In the TV drama under discussion, Haj Yunes (the father) frequently attacks the quality and social identity face of his younger son, Reza. Owing to his superiority as a father he has the option of using different abusive terms to intimidate and offend his son since, unlike his elder son, he has ideological differences with him. Reza's response options, on the other hand, are rather restricted since in Iranian culture children are expected to respect their parents even if they are the target of verbal abuse and offensive behavior. In one occasion, Reza's father even slapped him in the face, and instead of showing any aggressive reaction, he looked down and remained silent, a behavior that is unlikely to occur in the Western culture. Therefore, it can be concluded that the conceptualization and realization of impoliteness, particularly with reference to family hierarchy, is culture specific.

As mentioned above, Reza's response options were restricted. This finding supports Bousfield and Locher's (2008) assertion that "impoliteness - whether understood as intentional face-aggravation or not- is inextricably tied up with the very concept of power because an interlocutor whose face is damaged by an utterance suddenly finds his or her response options to be sharply restricted" (p.8-9).

Power-neutral situations in this study also led to both non-reciprocal and reciprocal impoliteness. The Persian utterances that were used in Excerpts 4 through 8 are potentially impolite in Iranian culture. However, given the intimate relationship between interlocutors, such face-attacks were not perceived as being genuine and impolite, hence they were not retaliated. This finding supports Locher and Watts' (2005) assertion that a seemingly impolite request like "Oi! Pen!” can be quite appropriate among friends. As they say, “...if the relationship between speaker and addressee is such that this form of behavior is interpretable as good-humored banter, it is likely to be perceived as perfectly appropriate to the social situation" (p.7). Based on this, they use the metaphor "politeness, like beauty, is in the eye of the beholder" (p. 21), emphasizing the hearer's perception in the interpretation of politeness.

On the other hand, in power-neutral contexts in which interlocutors had no history of friendship they reciprocated impoliteness fiercely attacking each other's face, as illustrated in Excerpts 9 through 11. In such cases, impoliteness is both intentional by the speaker and is perceived as being offensive by the listener. Contrary to this finding, Culpeper et al. (2003) did not find reciprocal impoliteness, or offensive-offensive pairs, as they call it, in their study presumably because the nature of their data was different from the present study. They explain lack of offensive-offensive pairs in their data as not being surprising since as they state, "whilst a clamper has the power to ticket, clamp or even tow away an owner's illegally parked vehicle, they do not 
in their particular socio-discoursal role have the legitimate power to respond to the impoliteness of car owners with clear, unambiguous impoliteness" (Culpeper et al., 2003, p.1563). This points to the significant role of relational context. The examples of reciprocal impoliteness in power-neutral situations found in Asheghaneh were cases of aggressive quarrels and fights where the role of power, if any, is not acknowledged.

As illustrated above (Section 3.2), when there is a mood change there is a shift to impoliteness disregarding power relation. However, although in such cases, power and status are no longer acknowledged, the weaker interlocutor may opt for reconciliation and avoid confrontation until he is pushed and forced to resort to impoliteness, as exemplified in Excerpt 3. Initially, Soheil tried to be patient and calm down his wife, who had power over him, by using polite and affectionate expressions, but since she continued attacking his social identity face in front of his friends (face-threat witnesses) he became enraged and attacked her verbally. Although the face-threat witnesses in this scene of the soap opera had a passive role and remained silent during the dispute between the couple their very presence affected Soheil's reaction to his wife's face threats. Mueller and Pillar's (2013) study also confirms the impact of face-threat witnesses on participants' reaction to impoliteness.

The fact that the characters in excerpt 3 were a young couple shows that even family members may fiercely attack each other's face pinpointing and highlighting the weaknesses of one another. This is in line with Birchler et al.'s (1975) finding (cited in Culpeper 1996, p. 354) that "even in happy marriages spouses were typically more hostile towards each other than strangers. In a familiar relationship one has more scope for impoliteness: one may know which aspects of face are particularly sensitive to attack, and one may be able to better predict and/or cope with retaliation that may ensue". Similar to this finding, Pegah and Soheil deliberately highlighted each other's weaknesses in order to intensify the degree of face-attack.

\section{CONCLUSION}

A general conclusion drawn from the present study's findings is the realization that people do not live in a philosopher's paradise to observe norms of politeness all the time. They may lose their temper, get angry, and sometimes engage in quarrels and fights in real-life situations. In such hostile situations, individuals deliberately and explicitly disrespect others and attack each other's faces, as the reciprocal cases of impoliteness in the drama illustrated. Based on the present study results, it can be concluded that the interpretation of impoliteness depends mainly on two main factors: the speaker's intention and (b) the perception of the addressee, whether s/he perceives of the utterance as being impolite or not. However, the interpretation of impoliteness varies according to relational contexts. As mentioned earlier, an identical utterance like khafe sho "shut up", which is potentially a face-threatening act in Persian, is not considered to be impolite among intimate friends. The data also point to the significance of the power relationship. As the results 
show, the speaker who has power over the addressee may intentionally attack their face, whereas the interlocutor who is in a subordinate position may try to manage and deflect impoliteness instead of retaliating impoliteness. However, when one's social identity face is attacked, the inferior may no longer tolerate impoliteness. In the case of the married couple (Pegah and Soheil), we saw that Pegah continuously attacked her husband's quality face when they were alone without being concerned about impoliteness being retaliated owing to the power that she had over him. However, when she started attacking his social identity face in front of others, he could not tolerate it anymore and attacked her face severely. From this, it can be concluded that impoliteness is co-constructed by interlocutors; hence responses to impoliteness should be discussed in the light of what triggers them. In the case of the preceding example, Soheil'sSoheil's retaliating face-attack was mainly triggered by the presence of the witnesses, in addition to his wife's impolite behavior.

The data analysis also shows that in cases of face-attacks, individuals have different options to respond to impoliteness. Some of these response strategies seem universal, and others are culture-specific. For instance, in quarrel scenes, face-attacks are universally expected to be retaliated and responded with face-attacks. In such hostile situations, the face of both interlocutors is significantly at stake. Some other strategies seem to be culture-specific. As illustrated above, in the case of family hierarchy in Iranian culture, impoliteness is tolerated. The person whose face has been attacked by a superior (e.g., one's father) may remain silent as a sign of respect.

It must be remembered that the findings of the present study are restricted to cases of impoliteness in a TV drama and are not generalizable to other genres and discourse types, such as political debates, academic discussions, and the like. It must be acknowledged that (im)politeness is a rather complex phenomenon; therefore, in the analysis and interpretation of impolite utterances, one has to consider different parameters and different contexts. Since the conceptualization of impoliteness may vary from culture to culture, a cross-cultural investigation of impoliteness is suggested for further research.

\section{REFERENCES}

Ahmed, A. (2012). Women and soap-operas: Popularity, portrayal and perception. International Journal of Scientific and Research Publications, 2(6), 1- 6.

Bousfield, D. (2008). Impoliteness in Interaction. Amsterdam: John Benjamins.

Bousfield, D. \& Locher, M. (Eds.) (2008). Impoliteness in Language: Studies on its Interplay with Power in Theory and Practice. Berlin: Mouton de Gruyter.

Brunsdon, C. (2000). The feminist, the housewife, and the soap opera. New York: Oxford.

Çevik, B. Senem (2014). Turkish Soap Opera Diplomacy: A Western Projection by a

Muslim Source. Exchange: The Journal of Public Diplomacy, 5 (1), 78-103.

Culpeper, J. (1996). Towards an anatomy of impoliteness. Journal of Pragmatics, 25(3), 349367. 
Culpeper, J. (2005). Impoliteness and entertainment in the television quiz show: The

Weakest Link. Journal of Politeness Research, 1(1), 35-72.

Culpeper, J. (2011). Politeness and impoliteness. In Karin Aijmer and Gisle Andersen (Eds.),

Pragmatics and Society, (pp. 391-436). Berlin: Mouton de Gruyter.

Culpeper, J., Boufield, D., \& Wichmann, A. (2003). Impoliteness revisited: with special reference to dynamic and prosodic aspects. Journal of Pragmatics, 35(10-11), 1545-1579.

Culpeper, J. \& Hardaker, C. (2017). Impoliteness. In Culpeper, J., Haugh, M., Kádár, D. (Eds.), Handbook of Linguistic (Im)Politeness (pp.199-225). Palgrave MacMillan, Basingstoke.

Dzo'ul Milal, A., Pramono, A. C. (2021). Impoliteness Addressed to Different Genders and their

Responses in The Kitchen Nightmares, a TV Reality Show. Journal of Pragmatics Research, 3(2), 131-146.

Gannon, C. (2009). Feminism \& soap opera. Social \& Political Review 19: 87-97. Dublin:

Trinity College.

Ghazzoul, N. (2019). Linguistic and pragmatic failure of Arab learners in direct polite requests and invitations: A cross-cultural study. Theory and Practice in Language Studies 9(2),

223-230. DOI: http://dsh.doi.org/10.17507/tpls.0902.13.

Harris, L., Gergen, K., \& Lannaman, J. (1986). Aggression Rituals. Communication Monographs, $53,252-265$.

Haryanti, R. Duwi (2016). A sociopragmatic analysis of interruptions by the male characters in Marc Cherry's Desperate Housewives, Season 1 TV series. MA thesis, Yogakarta State University, Indonesia.

Hohenstein, S. \& Thalmann, K. (2019). Difficult women: Changing representations of female characters in contemporary television series. Zeitschrift für Anglistik und Amerikanistik, 67(2), 109-129. https://doi.org/10.1515/zaa-2019-0012

Izzani, M. (2020). Address terms used by the characters of Brooklyn nine-nine television show: A sociopragmatic analysi. Bachelor thesis, Universitas Ahmad Dahlan.

Keshavarz, M. H., Cetereisi, Y, \& Asit, G. (2020). Pragmatic features of compliments in a Turkish TV drama. Journal of Pragmatic Research, 2(1), 1-25.

Khatib, M., \& Lotfi, K. (2015). Impoliteness and power: An interlanguage pragmatic approach to the use of impolite patterns in terms of power. Journal of English Language Teaching and Learning, 15, 43-67.

Khazdouzian, Y. (2018). The Effects of TV Series on Pragmatic Development. MA Thesis, Universitat de Barcelona, Spain.

Laitenen, M. (2011). Breaking the Rules of Communication: Verbal and Nonverbal Impoliteness in the American Hospital Drama House M.D. Master's Thesis. Jyväskylä: English Study Program, Department of Languages University of Jyväskilä. 
Lambertz, K., \& Hebrok, M. (2011). Women's Language in Soap Operas. Griffith Working Papers in Pragmatics and Intercultural Communication 4, 1(2), 39-54.

Limberg, H. (2009). Impoliteness and threat responses. Journal of Pragmatics, 41(7), 13761394.

Locher, M. (2006). Polite behaviour within relational work. The discursive approach to politeness. Multilingua 25(3), 249-267.

Locher, Marian A. \& Watts, Richard J. (2005). Politeness theory and relational work. Journal of Politeness Research 1(1), 9-33.

Mills, S. (2009). Impoliteness in a cultural context. Pragmatics 41(5), 1047-1060.

Mueller, A. \& Pilar, Garcés-Conejos B. (2013). Impoliteness in polylogal interaction: Accounting for face-threat witnesses' responses. Journal of Pragmatics 53: 112-130.

Rose, K. R. (2001). Compliments and compliment responses in film: Implications for pragmatics research and language teaching. International Review of Applied Linguistics, 39, 309-326

Van Der Bom, I. \& Mills, S. (2015). A discursive approach to the analysis of politeness data.

Journal of Politeness Research, 11(2), 179-206.

Watts, Richard J. (2003). Politeness. Cambridge: Cambridge University Press. 